\title{
Carcinogenicity of implanted synthetic grafts and devices
}

\author{
P. L. Dwyer • P. Riss
}

Published online: 11 March 2014

(C) The International Urogynecological Association 2014

Cancer in women is a common cause of morbidity and death, and the aetiology is frequently unknown. Potential carcinogenic agents are all around us: in the air we breathe, the food and fluids we digest, and in the background radiation that surrounds us. Also, diagnostic and therapeutic agents have the potential to induce cancer in some patients under some circumstances: X-ray investigations, radiation treatment, drugs and hormones with oestrogen are well-known examples. To prove these associations and calculate risk is always a long and arduous scientific process, but what can be even more difficult is to prove that there is no risk or association between various environmental factors or medical treatments and cancer. There will always be an inherent risk of cancer occurring in any individual, but is this increased, and if so by how much? A recent example is the reported association between mobile phone use, low-level exposure to radiofrequency electromagnetic fields and brain tumours. The evidence to date from multiple studies is that there is no increased risk of acoustic neuroma [1] or brain tumours [2], but larger and longer-term studies are needed.

Implantable devices and grafts also have the potential to induce cancer; thus, it is an important matter that is discussed by Ostergard and Azadi [3] in this issue of our journal. The authors raise the issue of the carcinogenicity of polypropylene (PPL) in animals and humans. Despite extensively searching the literature on PPL they found little evidence of carcinogenicity in humans, with only two cases in patients with polyester mesh grafts who had chronic infection and developed a

\section{P. L. Dwyer $(\bowtie)$}

Department of Obstetrics and Gynecology, Mercy Hospital for

Women, University of Melbourne, Melbourne, Australia

e-mail: pdwyer@connexus.net.au

\section{P. Riss}

Department of Gynecology and Obstetrics, Medical University of Vienna, Anna Frauer Gasse 2, 1180 Vienna, Austria squamous cell carcinoma 6 and 24 years following insertion [4]. As stated by Ostergard and Azadi [3], chronic inflammation of long duration is a known cause of cancer. The mesh did contribute to the infection and inflammation, but is it in itself carcinogenic?

By 3 months after implantation, PPL mesh is surrounded by mature connective tissue and only rarely becomes infected unless inappropriately situated, for instance, protruding into the bowel, bladder or vagina. Synthetic mesh, including PPL, has been used in urogynaecological surgery since the 1960s $[5,6]$, and even more widely in other forms of reconstructive surgery, such as hernia repair. Despite the millions of patients worldwide who have had PPL implanted, the authors could find no evidence of an association with cancer, or any case reports. This should give our patients considerable confidence that their PPL implants will not cause cancer. However, there are risks associated with graft and mesh usage; these do need to be carefully weighed against the potential benefits when used in reconstructive surgery.

We have balanced the Ostergard and Azadi article with two other contributions written by experts in urogynaecology and PPL mesh and biomaterials [7, 8]. We hope that open discussion leads to a better understanding of this sensitive issue, not only by clinicians, but also, just as importantly, by the broader community, who can be reassured that even the most difficult issues will be scientifically assessed and discussed.

\section{References}

1. INTERPHONE Study Group (2011) Acoustic neuroma risk in relation to mobile telephone use: results of the INTERPHONE international case-control study. Cancer Epidemiol 35(5):453-464

2. INTERPHONE Study Group (2010) Brain tumour risk in relation to mobile telephone use: results of the INTERPHONE international casecontrol study. Int J Epidemiol 39:675-694 
3. Ostergard DR, Azadi A (2014) To mesh or not to mesh with polypropylene: does carcinogenesis in animals matter? Int Urogynecol J. doi: 10.1007/s00192-013-2239-z

4. Birolini C, Minossi JG, Lima CF, Utiyama EM, Rasslan (2013) Mesh cancer: Long-term mesh infection leading to squamous-cell carcinoma of the abdominal wall. Hernia doi: 10.1007/s10029-013-1083-x

5. Moir JC (1968) The gauze/hammock operation (a modified Aldridge sling procedure). J Obstet Gynaecol Br Commonw 75(1):1-9
6. Morgan JE (1970) A sling using Marlex polypropylene mesh for treatment of recurrent stress incontinence. Am J Obstet Gynecol 106 (3):369-377

7. Nager $\mathrm{C}$ et al (2014) Polypropylene mesh: evidence for lack of carcinogenicity. Int Urogynecol J doi:10.1007/s00192-014-2343-8

8. Williams DF (2014) Carcinogenicity of implantable materials: the experimental and epidemiological evidence. Int Urogynecol J doi:10. 1007/s00192-014-2346-5 